\title{
Prediction by data mining, of suicide attempts in Korean adolescents: a national study
}

\author{
This article was published in the following Dove Press journal: \\ Neuropsychiatric Disease and Treatment \\ 16 September 2015 \\ Number of times this article has been viewed
}

\author{
Sung Man Bae' \\ Seung A Lee ${ }^{2}$ \\ Seung-Hwan Lee ${ }^{2,3}$ \\ 'Department of Counseling \\ Psychology, The Cyber University of \\ Korea, Seoul, South Korea; ${ }^{2}$ Clinical \\ Emotion and Cognition Research \\ Laboratory, Goyang, South Korea; \\ ${ }^{3}$ Department of Psychiatry, Ilsan Paik \\ Hospital, Inje University College of \\ Medicine, Goyang, South Korea
}

Objective: This study aimed to develop a prediction model for suicide attempts in Korean adolescents

Methods: We conducted a decision tree analysis of 2,754 middle and high school students nationwide. We fixed suicide attempt as the dependent variable and eleven sociodemographic, intrapersonal, and extrapersonal variables as independent variables.

Results: The rate of suicide attempts of the total sample was $9.5 \%$, and severity of depression was the strongest variable to predict suicide attempt. The rates of suicide attempts in the depression and potential depression groups were 5.4 and 2.8 times higher than that of the nondepression group. In the depression group, the most powerful factor to predict a suicide attempt was delinquency, and the rate of suicide attempts in those in the depression group with higher delinquency was two times higher than in those in the depression group with lower delinquency. Of special note, the rate of suicide attempts in the depressed females with higher delinquency was the highest. Interestingly, in the potential depression group, the most impactful factor to predict a suicide attempt was intimacy with family, and the rate of suicide attempts of those in the potential depression group with lower intimacy with family was 2.4 times higher than that of those in the potential depression group with higher intimacy with family. And, among the potential depression group, middle school students with lower intimacy with family had a 2.5-times higher rate of suicide attempts than high school students with lower intimacy with family. Finally, in the non-depression group, stress level was the most powerful factor to predict a suicide attempt. Among the non-depression group, students who reported high levels of stress showed an 8.3-times higher rate of suicide attempts than students who reported average levels of stress.

Discussion: Based on the results, we especially need to pay attention to depressed females with higher delinquency and those with potential depression with lower intimacy with family to prevent suicide attempts in teenagers.

Keywords: predictor, severity of depression, suicide, delinquency, intimacy with family

\section{Introduction}

The rate of completed suicide in South Korea in 2011 was 33.3 in 100,000, which is significantly higher compared to that in other developed countries, including the United States (12.5), the United Kingdom (6.7), Germany (10.8), Australia (10.1), and Japan (20.9). ${ }^{1}$ Suicide attempts in adolescents, in particular, are increasing rapidly and suicide is becoming one of the serious social issues in South Korea. Actually, the rate of completed suicide of Korean adolescents was $4.4 \%$ in 2012 . $^{2}$

In previous studies, depression was considered to be the main predictor of suicide attempts, and it is known that suicide attempts for all ages are affected by depression. 3.4 Adolescents, who are more impulsive and emotionally unstable compared to adults, are likely to attempt suicide unexpectedly, either when they are very depressive or 
shortly after recovery from a depressive state. ${ }^{5}$ Daily stress is another main predictor of suicide attempts, and it could affect suicide attempts directly or through interaction with depression. ${ }^{6}$ The stress level from daily life, such as from academic competition or conflict with parents or the peer group, was found to significantly predict suicide attempts in adolescents. ${ }^{7}$

Some studies have suggested delinquency as an important predictor of suicide attempts. ${ }^{8,9}$ Juvenile delinquency occurs frequently along with depression, ${ }^{10}$ and an interaction between them would have some causal effects on completed suicide. Also, juvenile delinquency could be predicted by relationships with peers, parents, and teachers, as well as by stress and adjustments at school. ${ }^{11}$ According to the problem behavior theory of Jessor, ${ }^{12}$ perceived environment variables such as parent-child conflict and peer relationship problems affect problem behaviors (eg, delinquency, conduct problems), and problem behaviors can impact other emotional and behavioral problems (eg, depression, internet addiction, suicide attempt). ${ }^{9}$

Optimism is considered to be an important variable of mental health. Optimistic persons experience positive emotions more frequently, and their level of worrying, anxiousness, or depression was found to be lower compared to those of pessimistic people. ${ }^{13}$ Hirsch et al reported that optimism decreased suicidal ideation even after covariates such as age, sex, and depression symptoms are controlled. ${ }^{14}$ Also, Seo reported that optimism, family environment, school life, or community activities affect suicidal ideation by mediating depression and hopelessness in high school students. ${ }^{15}$

In adolescents, relationship with parents is an important predictor of suicide ideation. ${ }^{16,17}$ Close intimacy with parents helps adolescents to maintain emotional stability and develop self-esteem. Furthermore, it was revealed that good intrafamilial relationships prevented suicide attempts in depressed adolescents. ${ }^{18,19}$ Self-esteem could be another major predictor of suicide. Adolescents with a high level of self-esteem showed a lower frequency of suicide ideation and attempts. ${ }^{20}$

Joiner insisted that suicide risk is increased by thwarted belongingness and perceived burdensomeness from relationships with others. ${ }^{21}$ It could be assumed that community support and interaction with the community could become predictors of suicide ideation and attempts. A person can experience self-worth and feel less loneliness and alienation when community support and interaction are abundant. These would act as buffers for negative thoughts when people are in stressful situations and eventually reduce the risk of completed suicide. ${ }^{22,23}$

As happiness and satisfaction of adolescents are closely related to school life, an adolescent's suicide attempt is highly linked to academic achievement and adjustment at school. Conflict with peers is one of the primary factors for stress, and peer conflicts could have significant effects on suicide attempts in adolescents. ${ }^{24,25}$ Good relationships with teachers also have buffering effects on stress. Especially for Korean adolescents, academic achievement is another major stressful factor which could affect suicide attempts in adolescents. ${ }^{26}$

Previous studies have selected suicide ideation as the dependent variable. However, considering that completed suicide follows after suicide ideation and suicide attempt, ${ }^{18}$ selecting suicide attempt as the dependent variable would allow us to make more accurate predictions of completed suicide and develop a theoretical framework for early intervention. Moreover, most studies did not consider sociodemographic and psychological variables together relevant to suicide. Particularly, sex,${ }^{27}$ socioeconomic status, ${ }^{28}$ and parents' academic backgrounds have been revealed as important variables that could predict suicide attempts or completed suicide.

We assumed that interaction between sociodemographic and psychological variables could be important to predicting suicide attempts. The current study tried to develop a model to predict suicide attempts in Korean adolescent using decision tree analysis, which is a well-known useful statistical method to analyze all interaction effects of multiple variables. The purpose of this study was the development of a predictive model of suicide attempts. We considered all interactions of sociodemographic variables and eight intrapersonal and extrapersonal variables (depression, stress, delinquency, selfesteem, intimacy with family, optimism, school adaptation, and community support and interaction) for middle and high school students.

\section{Methods}

\section{Participants and procedure}

The current study utilized data from the survey of mental health in 2011 from the National Youth Policy Institute of Korea. Sixteen metropolitan cities and provinces (Seoul, Busan, Daegu, Incheon, Kwangju, Daejeon, Ulsan, Gyeonggi, Gangwon, Chungbuk, Chungnam, Jeonbuk, Jeonnam, Gyeongbuk, Gyeongnam, Jeju) and school level (middle or high) were selected as stratifying variables. Population size was determined by proportional allocation. 
Data were collected from a class in one grade level of each school allocated in each city. The total sample consisted of 2,754 middle and high school students (1,110 males, 1,644 females). Sociodemographic characteristics of the participants are shown in Table 1.

The current study attempted to develop a prediction model for suicide attempts by including eleven sociodemographic variables and eight psychological variables. In order to investigate which variables affect suicide attempts in different levels of depression, students were divided into three groups based on depression severity, which is the primary predictor variable of suicide attempt or completed suicide. This study was approved by the Institutional Review Board of Inje University Ilsan Paik Hospital (Goyang, South Korea). The study was exempted from the requirement of informed consent by the board.

\section{Measures}

\section{Suicide attempt}

Suicide attempt was measured by a single-item scale ("Did you attempt suicide in the last 1 year?"). Students were required to make a two-alternative forced choice ("yes" or "no").

\section{Sociodemographic variables}

In the current study, the nine sociodemographic variables predicting suicide attempt were selected as follows: sex, age, school level (middle or high school), school record (excellent, good, average, poor, bad), academic backgrounds of father and mother, employment statuses of father and

Table I Sociodemographic characteristics

\begin{tabular}{|c|c|c|}
\hline \multirow[t]{2}{*}{ Variable } & \multirow{2}{*}{$\begin{array}{l}\text { Sample size } \\
\text { (persons) } \\
2,754\end{array}$} & \multirow{2}{*}{$\begin{array}{l}\text { Rate (\%) } \\
100\end{array}$} \\
\hline & & \\
\hline \multicolumn{3}{|l|}{ Sex } \\
\hline Male & 1,110 & 40.3 \\
\hline Female & 1,644 & 59.7 \\
\hline \multicolumn{3}{|l|}{ School level } \\
\hline Middle school & $\mathrm{I}, 208$ & 43.9 \\
\hline High school & $\mathrm{I}, 546$ & 56.1 \\
\hline \multicolumn{3}{|l|}{ Location of school } \\
\hline Metropolitan & 1,137 & 41.3 \\
\hline Micropolitan & 1,326 & 48.1 \\
\hline Rural areas & 291 & 10.6 \\
\hline \multicolumn{3}{|c|}{ Socioeconomic status } \\
\hline High & 338 & 12.3 \\
\hline Middle & 2,168 & 78.7 \\
\hline Low & $24 I$ & 8.9 \\
\hline Non-response & 7 & 0.3 \\
\hline
\end{tabular}

mother, location of school (metropolitan, micropolitan, rural areas), socioeconomic status (high, middle, low), and family structure (two parents, single parent, divorced parent, custodial grandparents, etc).

\section{Depression}

The Beck Depression Inventory (BDI) ${ }^{29}$ was used to measure depression levels in the adolescents. There are 21 items with a four-point scale, totaling 63 points. Scores greater than 18 are taken to indicate depression. Internal consistency of the current data was 0.900 .

\section{Stress}

A daily stress questionnaire ${ }^{30}$ developed by the National Youth Policy Institute of South Korea was used. Daily stress was measured based on 12 categories (relationships with parents, siblings, friends, the opposite sex, colleagues, and teachers; appearance; physical health; mental health; financial problems; and academic stress) with a four-point scale (not at all influenced, not very influenced, somewhat influenced, very influenced). Internal consistency of the current data was 0.910 .

\section{Delinquency}

A delinquency questionnaire ${ }^{30}$ developed by the National Youth Policy Institute of South Korea was used. Delinquent behavior within the last 1 year was measured by ten items (smoking, drinking alcohol, theft, use of violence, extortion, absence without leave, running away from home, watching pornography, gambling, and damaging public property) with a four-point scale (none, one to three times, three to four times, over five times). Internal consistency of the current data was 0.812 .

\section{Self-esteem}

A self-esteem scale ${ }^{30}$ developed by the National Youth Policy Institute of South Korea was used to measure self-esteem. The level of self-esteem was evaluated with five items with a four-point scale. A higher score denotes a higher level of self-esteem. Internal consistency of the current data was 0.902 .

\section{Optimism}

An optimism questionnaire ${ }^{30}$ developed by the National Youth Policy Institute of South Korea was used. Three items with a four-point Likert scale were used to measure whether students believed themselves to be able to control their own lives and whether they viewed themselves and global affairs 
positively and optimistically. Internal consistency of the current data was 0.794 .

\section{Intimacy with family}

A questionnaire ${ }^{30}$ developed by the National Youth Policy Institute of South Korea was used for evaluation of intimacy with family. Intimacy with family was measured by five items with a four-point scale. A higher score denotes closer intimacy with family. Internal consistency for the current data was 0.924 .

\section{Community support and interaction}

A questionnaire ${ }^{30}$ developed by the National Youth Policy Institute of South Korea was used for evaluation of community support and interaction. Three items for community support and another three items to measure interaction with community, totaling six items, were used. Community support indicates a person (except family, friends, or teachers) or organization which one can trust or seek help from when in need. Interaction with community implies involvement in volunteering or activities with community organizations. Internal consistency for community support was 0.828 , for interaction with community was 0.765 , and for total data was 0.811 .

\section{Adjustment to school}

A questionnaire ${ }^{30}$ developed by the National Youth Policy Institute of South Korea was used for evaluation of adjustment to school. Twelve items with a four-point scale measured the level of each adolescent's adjustment to school. There are four indexes, covering attitude toward class, relationships with teachers and with peers, and school life. Each of the four indexes is comprised of three items. Internal consistency for school class is 0.814 , for relationship with teacher is 0.875 , for relationship with peers is 0.843 , for school life is 0.712 and for total data is 0.861 .

\section{Data analysis}

The current study used the Answer Tree 3.0 program to conduct a decision tree analysis of data mining. Data mining is efficient for analyzing big data because every possible interaction between a great number of variables, including continuous and dichotomous variables, can be analyzed. In contrast to typical statistical hypothesis testing, data mining does not establish a specific hypothesis. In data mining, explanation of the results from the big data analysis is essential.
For splitting criteria in the decision tree analysis, we employed chi-squared automatic interaction detection (CHAID). Although CHAID can predict both continuous and dichotomous target variables, it is more apt for prediction of a dichotomous target variable. As the target variable in the current study was dichotomous (did attempt suicide or did not attempt suicide), multiway split was conducted by chi-square test. In multiway split, more than two child nodes are separated from a parent node. The stopping rule for maximum tree depth is a value of 5 , and the minimum numbers of cases for parent and child nodes are 50 and 25 , respectively. Gain charts and risk charts are applied to test the fitness of the model. Gain chart is the ratio of the target category (suicide attempt for the current study) in a particular node. Risk chart is the probability that a model misclassifies an observation.

We divided the total sample into training data $(70 \%$ of total sample) and testing data (30\% of total sample). Firstly, to develop the best prediction model for suicide attempts, we utilized training data and identified the possibility of generalization of the prediction model through testing data. If there is no difference in risk estimates of the model between training data and testing data, generalization of training data can be assumed.

\section{Results}

The outcomes from the decision tree analysis of the training sample were as follows (Figure 1). Firstly, approximately $9.64 \%(n=186)$ out of a total of 1,910 students (training sample) reported that they had attempted suicide. Those who had never attempted suicide was 90.36\% $(n=1,744)$. Secondly, depression was the primary variable predicting suicide attempts in adolescents (chi-square: 101.3982, $P<0.0001$ ). The rate of suicide attempts was $20.34 \%$ in the depression group ( $\mathrm{n}=531), 7.32 \%$ in the potential depression group $(n=710)$, and $3.77 \%$ in the non-depression group $(n=689)$.

The rate of suicide attempts in the depression group was different according to delinquency level (chi-square: 13.6599, $P<0.0028)$. Of depressed students with a high score for delinquency (delinquency $>19$, $n=78$ ), 35.90\% showed a suicide attempt, while $17.66 \%$ of depressed students with a low score for delinquency (delinquency $\leq 19, \mathrm{n}=453$ ) showed a suicide attempt. The rate of suicide attempts of those in the depression group with a high score for delinquency was different according to sex (chi-square: 4.6897, $P<0.0303$ ). The rate of suicide attempts of females with a high score for delinquency in the depression group $(\mathrm{n}=32)$ was $50.00 \%$, while the rate of suicide attempts of males with a high score for delinquency 


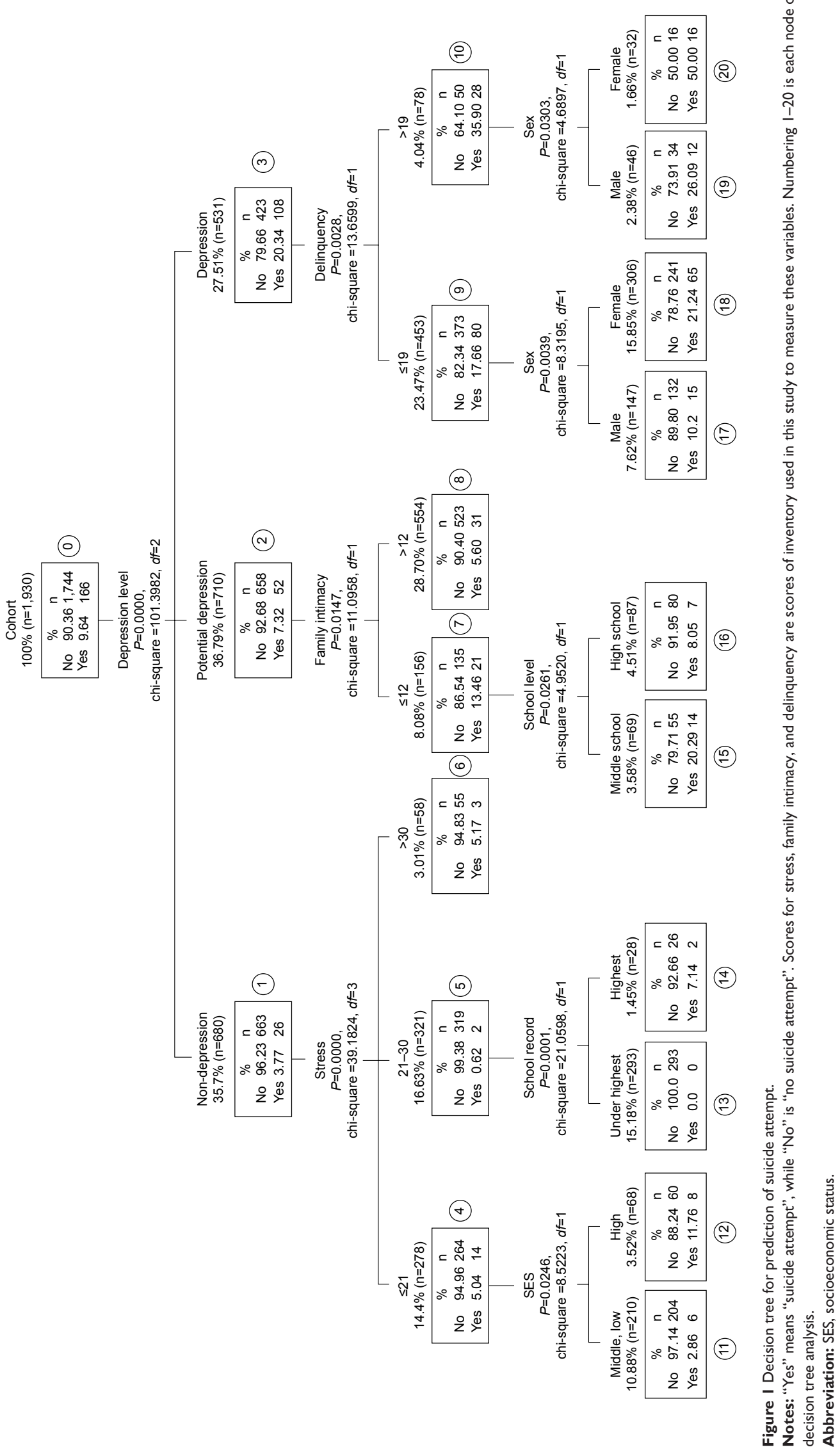


Table 2 Gain index of predicting suicide attempts

\begin{tabular}{|c|c|c|c|c|c|c|c|c|c|c|c|c|}
\hline \multirow[t]{2}{*}{ Node } & \multicolumn{6}{|c|}{ Gain index } & \multicolumn{6}{|c|}{ Accumulated gain index } \\
\hline & Node: $\mathbf{n}$ & Node: $\%$ & Gain: $\mathbf{n}$ & Gain: \% & Resp: \% & Index: \% & Node: $\mathbf{n}$ & Node: \% & Gain: $\mathbf{n}$ & Gain: \% & Resp: \% & Index: \% \\
\hline 20 & 32 & 1.7 & 16 & 8.6 & 50.0 & 518.8 & 32 & 1.7 & 16 & 8.6 & 50.0 & 518.8 \\
\hline 19 & 46 & 2.4 & 12 & 6.5 & 26.1 & 270.7 & 78 & 4.0 & 28 & 15.1 & 35.9 & 372.5 \\
\hline 18 & 306 & 15.9 & 65 & 34.9 & 21.2 & 220.4 & 416 & 21.6 & 100 & 53.8 & 24.0 & 249.4 \\
\hline 15 & 69 & 3.6 & 14 & 7.5 & 20.3 & 210.5 & 485 & 25.1 & 114 & 61.3 & 23.5 & 243.9 \\
\hline 12 & 68 & 3.5 & 8 & 4.3 & 11.8 & 122.1 & 553 & 28.7 & 122 & 65.6 & 22.1 & 228.9 \\
\hline 17 & 147 & 7.6 & 15 & 8.1 & 10.2 & 105.8 & 700 & 36.3 & 137 & 73.7 & 19.6 & 203.1 \\
\hline 16 & 87 & 4.5 & 7 & 3.6 & 8.0 & 83.5 & 787 & 40.8 & 144 & 77.4 & 18.3 & 189.9 \\
\hline 14 & 28 & 1.5 & 2 & I.I & 7.1 & 74.1 & 815 & 42.2 & 146 & 78.5 & 17.9 & 185.9 \\
\hline 8 & 554 & 28.7 & 31 & 16.7 & 5.6 & 58.1 & 1,369 & 70.9 & 177 & 95.2 & 12.9 & 134.2 \\
\hline 6 & 58 & 3.0 & 3 & 1.6 & 5.2 & 53.7 & I,427 & 73.9 & 180 & 96.8 & 12.6 & 130.9 \\
\hline 11 & 210 & 10.9 & 6 & 3.2 & 2.9 & 29.6 & $\mathrm{I}, 637$ & 84.8 & 186 & 100.0 & II.4 & 117.9 \\
\hline 13 & 293 & 15.2 & 0 & 0 & 0 & 0 & 1,930 & 100.0 & 186 & 100.0 & 9.6 & 100.0 \\
\hline
\end{tabular}

Notes: Node = each node number. Node: $n=$ sample size of each node. Node: $\%=$ rate of target category of total sample. Gain: $n=$ sample size of target category of each node. Gain: \% = rate of target category of each node of total target category. Resp: \% = rate of sample size of target category of sample size of each node. Index: \% = resp (\%) versus rate of target category of sample size.

$(n=46)$ was $26.09 \%$. Also, the rate of suicide attempts of those in the depressed group with a low score for delinquency was different according to sex (chi-square: 8.3195, $P<0.0039$ ). The rate of suicide attempts in depressed males with a low score for delinquency $(\mathrm{n}=147)$ was $10.20 \%$ and in females ( $n=306$ ) was $21.24 \%$. To sum up, in the depressed group, female students with a high score for delinquency had the highest rate of suicide attempts.

In the potential depression group, the rate of suicide attempts was different according to intimacy with family (chi-square: 11.0958, $P<0.0147$ ). Students with a high level of intimacy with family (intimacy with family $>12, n=554$ ) showed a rate of suicide attempts of $5.60 \%$, while those with a low level of intimacy with family (intimacy with family $\leq 12$, $\mathrm{n}=156$ ) showed a rate of suicide attempts of $13.46 \%$. In addition, the rate of suicide attempts for those with a low level of intimacy with family in the potential depression group was different according to school level (chi-square: 4.9520, $P<0.0261$ ). The rate of suicide attempts of middle school students with low intimacy with family $(\mathrm{n}=69)$ was $20.09 \%$, while the rate of suicide attempts of high school students with low intimacy with family $(\mathrm{n}=87$ ) was $8.05 \%$.

In the non-depression group, the rate of suicide attempts was different according to stress level (chi-square: 39.3824, $P<0.0001$ ). Students who had a high level of stress (stress level $\geq 30, n=58$ ) showed a rate of suicide attempts of $5.17 \%$, while those with a middle level of stress $(21<$ stress level $<30, \mathrm{n}=321$ ) showed $0.62 \%$, and students with a low level of stress (stress level $\leq 21, \mathrm{n}=278$ ) showed $5.04 \%$. In students with a low stress level among the nondepression group, the rate of suicide attempts was different according to school record (chi-square: 21.0598, $P<0.0001$ ).
Among students with a middle level of stress in the nondepression group, the rate of suicide attempts of students who reported that their school record was excellent $(n=28)$ was $7.14 \%$. On the other hand, the rate of suicide attempts for those whose school record was below excellent (good, average, poor, bad, $\mathrm{n}=293$ ) was $0 \%$.

The gain chart in Table 2 provides legends for each node of target category (suicide attempt). The gain chart consists of node-by-node statistics (gain index) and cumulative statistics (accumulated gain index). The highest gain score for the current study was the 20th node, which was the depressed females with a high level of delinquency. The number of cases in the 20th node was 32 out of the total 1,930 samples, which is $1.7 \%$ of the total subjects. Among cases in the 20th node ( $n=32)$, the number of cases which corresponded to the target category (gain: n) was 16 students, which is $50 \%$ of the total number of cases in the 20th node (response: \%). Response (\%) in the 20th node was five times greater than the rate of the target category $(9.64 \%)$ of total samples $(1,930)$. Finally, the index (\%) of the 20th node was $518.8 \%$. Although there are no clear criteria for index (\%), index (\%) over $200 \%$ at a particular node is generally considered to be a high gain score.

The risk estimate of the final model for training data is shown in Table 3. Risk estimates are the prediction error rates of the final model. The prediction error rate in the current study was $9.64 \%$, and the accuracy of classification was over $90 \%$.

Table 3 Risk estimate for prediction of suicide attempt

\begin{tabular}{ll}
\hline & Final value \\
\hline Risk estimates & 0.0963731 \\
Standard error & 0.00671728 \\
\hline
\end{tabular}


In the current study, validity testing for training data was conducted to ensure generalization of the prediction model for suicide attempts. The validity testing of training data through testing data $(\mathrm{n}=824)$ showed that the risk estimate of the testing sample was 0.092233 and it was not significantly different from the risk estimate $(0.0963731)$ of the training data. Therefore, it seems the prediction model for suicide attempts in the current study has a high possibility of generalization.

\section{Discussion}

The current study attempted to develop the best-fit model for the prediction of suicide attempts in Korean adolescents by analyzing every possible interaction between eleven sociodemographic and eight psychological variables. The results showed that: 1) the primary predictive variable for suicide attempts in adolescents was severity of depression; 2) juvenile delinquency was the primary variable for prediction of suicide attempts in the depression group; 3 ) intimacy with family was the primary variable in the potential depression group; and, finally, 4) stress was the primary predictive variable for suicide attempts in the non-depression group.

Decision tree analysis showed that severity of depression was the primary variable for prediction of suicide attempts in Korean adolescents. The rate of suicide attempts was 2.8 times higher in the depression group compared to the potential depression group. Compared to the non-depression group, the depression group had a 5.4-times higher rate of suicide attempts. These results are consistent with previous findings that have revealed depression as the strongest predictive variable for suicide ideation, plans, and attempts in all ages. ${ }^{31,32}$

Juvenile delinquency was the primary factor in the depression group. Those in the depression group with a high level of delinquency had a two-times higher risk for suicide attempts than those in the depression group with a low level of delinquency. Whereas predictors like depression or stress have been well studied, the influence of delinquency on suicide attempts has been found in relatively few studies. ${ }^{33,34}$ Moreover, coexistence rate of conduct disorder, which includes delinquency and depression is high. ${ }^{35}$ Our results suggest that risk for suicide attempts would rapidly increase if depressed adolescents showed delinquent behaviors in addition.

Furthermore, in the depression group, girls with a high level of delinquency had a $50 \%$ rate of suicide attempts. Interestingly, the rate of suicide attempts was 1.9 times higher in depressed females with a high level of delinquency compared to depressed males with a high level of delinquency, although there were more males with delinquent behavior.
Combined with previous studies, the current results show that sex as well as delinquency are important predictive factors for suicide attempts. ${ }^{36}$ Because female delinquency is less likely than male delinquency, female delinquency could be deemed more serious by friends or others. ${ }^{34}$ Also, delinquency in female students could make it more difficult for them to adjust at school and lead to them experiencing depression or attempting suicide.

In contrast to the depression group, the potential depression group showed that intimacy with family was the primary variable in prediction of suicide attempts. Those in the potential depression group with a low level of family intimacy showed a 2.5-times higher rate of suicide attempts compared to those in the potential depression group with a high level of family intimacy. These results are consistent with previous studies that also found family-related variables are important in the prediction of adolescent suicide. ${ }^{37,38}$ The intimacy with family variable was included in the predictive model of our study instead of self-esteem, optimism, community support and interaction, and school adjustment. This implies that family-related variables should receive more focus in the prediction of suicide attempts in adolescents. Intimacy with family and psychological support from family can be buffers for stressful situations such as an entrance examination for college. ${ }^{32}$ Therefore, it is strongly suggested that clinicians should pay more attention to depression and family function in preventing suicide attempts and completed suicide.

In the potential depression group, middle school students with low family intimacy had a 2.5 -times greater risk for suicide attempts compared to high school students with low family intimacy. In middle school students, stresses from school work, peer relationships, and school adjustment are radically increased, while their self-identity and cognitive abilities (eg, integrated thinking, cognitive flexibility) are less developed. In this situation, intimacy with family can be an important factor to buffer these stresses arising from psychological and environmental issues. It is important for parents to share emotional intimacy with them in order to prevent completed suicide in adolescence.

In the non-depression group, those with high levels of stress had a 3.8-times greater risk for suicide attempts compared to those with middle levels of stress, ${ }^{39,40}$ while those with low levels of stress had an almost equal propensity to attempt suicide as those with high levels of stress. Research by Feskanich et al in 94,110 female nurses, similar to this study, showed that the rate of suicide attempts of those with minimal and moderate levels of stress was higher than that of people who reported light levels of stress. ${ }^{41}$ Why is there a U-shaped curve (the 
rate of suicide attempt of person with mild or middle level of stress) around stress and suicide attempts for this without depression? Adolescents who reported mild levels of stress in this study may deny stress, and a coping mechanism of denial may be another risk factor of suicide attempts. ${ }^{42}$

In addition, those who reported middle levels of stress in the non-depression group showed a different rate of suicide attempts according to their school record. Students with the "highest" (excellent) school record had a seven-times greater risk for suicide attempts compared to those with "under highest" (good, average, poor, and bad). Students who have been very good at schoolwork are relatively more likely to experience academic stress than other students. Some of these students become frustrated and can perform extreme behaviors even if their grade falls a little.

In this study, self-esteem and school adjustment variables were excluded in the present model, despite those variables having been considered to be important predictive factors in previous studies. ${ }^{18,20}$ This implies that these excluded variables may play a less significant role in interaction with other variables for prediction of suicide attempts.

The clinical values of this study are as follows. Firstly, suicide attempt was used as the dependent variable, which is the most relevant variable with completed suicide. As a result, more accurate prediction of completed suicide could be made. Bridge et al showed that a person who has attempted suicide is at an over 60-times greater risk for committing completed suicide compared to those who have never attempted suicide. ${ }^{43}$ Secondly, decision tree analysis made it possible to analyze every possible interaction between sociodemographic and psychological variables to improve the precision of the prediction model. Thirdly, considering depression severity in predicting suicide attempts seems be a new direction. Results of the current study indicate that a different approach according to severity of depression is required in order to prevent suicide attempts in adolescents.

\section{Conclusion}

Our model suggests that adolescents with different severities of depression show distinctive pathways to suicide attempts. Severity of depression should be considered above all, to predict suicide attempts. Delinquency and sex were important variables to predict suicide attempts in depressed adolescents. Intimacy with family was a significant variable to predict suicide attempts in the potential depression group. Interestingly, school performance record was a significant variable to predict suicide attempts in the non-depression group of Korean adolescents.

\section{Acknowledgment}

This study used the data from the survey of mental health in 2011 from the National Youth Policy Institute. This research was supported by Basic Science Research Program through the National Research Foundation of Korea (NRF) funded by the Ministry of Education, Science and technology (No. 2012R1A1A2043992).

\section{Disclosure}

The authors report no conflicts of interest in this work.

\section{References}

1. Choi YN, Kim YA, Yun YH, et al. Suicide ideation in stomach cancer survivors and possible risk factors. Support Care Cancer. 2014;22(2): 331-337.

2. Ahn JH, Han CS, Woo JM, Kim GM. A Study on Korean Psychiatric Disorder Research: Depression and Suicide. Seoul: National Evidencebased Collaborating Agency; 2012. Available from http://yhs.cdc.go.kr/ upload/thesis/20130104144715180.pdf. Korean.

3. Foley DL, Goldston DB, Costello EJ, Angold A. Proximal psychiatric risk factors for suicidality in youth: the Great Smoky Mountains Study. Arch Gen Psychiatry. 2006;63(9):1017-1024.

4. Rohde P, Lewinsohn PM, Klein DN, Seeley JR, Gau JM. Key characteristics of major depressive disorder occurring in childhood, adolescence, emerging adulthood, and adulthood. Clin Psychol Sci. 2013; $1:(1)$.

5. Lewis AJ, Bertino MD, Bailey CM, Skewes J, Lubman DI, Toumbourou JW. Depression and suicidal behavior in adolescents: a multi-informant and multi-methods approach to diagnostic classification. Front Psychol. 2014;5:766.

6. McKeown RE, Garrison CZ, Cuffe SP, Waller JL, Jackson KL, Addy CL. Incidence and predictors of suicidal behaviors in a longitudinal sample of young adolescents. J Am Acad Child Adolesc Psychiatry. 1998;37(6):612-619.

7. Wilson KG, Stelzer J, Bergman JN, Kral MJ, Inayatullah M, Elliott CA. Problem solving, stress, and coping in adolescent suicide attempts. Suicide Life Threat Behav. 1995;25(2):241-252.

8. Corneau M, Lanctôt N. Mental health outcomes of adjudicated males and females: the aftermath of juvenile delinquency and problem behaviour. Crim Behav Ment Health. 2004;14(4):251-262.

9. Thompson MP, Kingree JB, Ho CH. Associations between delinquency and suicidal behaviors in a nationally representative sample of adolescents. Suicide Life Threat Behav. 2006;36(1):57-64.

10. American Psychiatric Association. Diagnostic and Statistical Manual of Mental Disorders, Fourth Edition, Text Revision (DSM-IV-TR). Washington: American Psychiatric Association; 2000.

11. Wo C, Kim P. The multidimensional structure analysis of variables related to adolescents' suicidal ideation. Korean Journal of Youth Studies. 2011;18(4):219-240. Korean.

12. Jessor R. Risk behavior in adolescence: a psychosocial framework for understanding and action. J Adolesc Health. 1991;12:587-605.

13. Sim M, Kim K. Risk and protective factors for suicidal ideation of Korean adolescents: Moderating effect of sex and developmental period. The Korean Journal of Health Psychology. 2005;10:313-325. Korean.

14. Hirsch JK, Conner KR, Duberstein PR. Optimism and suicide ideation among young adult college students. Arch Suicide Res. 2007;11(2):177-185.

15. Seo H. Structural equational modeling for high school students's suicide thinking. Korean Journal of Youth Studies. 2006;13:207-232. Korean.

16. Lee J, Kim H, Hyun M. The relationship of stress, parent-adolescent communication and suicide ideation among adolescent. The Korean Journal of Health Psychology. 2005;10(4):375-394. Korean. 
17. Perkins DF, Hartless G. An ecological risk-factor examination of suicide ideation and behavior of adolescents. J Adolesc Res. 2002;17(1):3-26.

18. Choi I. Parents-adolescent relationship's influence on adolescent's suicidal ideation: focused on mediating effects of adolescent's self-esteem and depression. Korean Journal of Youth Studies. 2010;17:105-130. Korean.

19. Consoli A, Peyre H, Speranza M, et al. Suicidal behaviors in depressed adolescents: role of perceived relationships in the family. Child Adolesc Psychiatry Ment Health. 2013;7(1):8.

20. Overholser JC, Adams DM, Lehnert KL, Brinkman DC. Self-esteem deficits and suicidal tendencies among adolescents. J Am Acad Child Adolesc Psychiatry. 1995;34(7):919-928.

21. Joiner T. Why People Die by Suicide. Harvard University Press; 2009. ISBN 9780674025493.

22. Czyz EK, Liu Z, King CA. Social connectedness and one-year trajectories among suicidal adolescents following psychiatric hospitalization. J Clin Child Adolesc Psychol. 2012;41(2):214-226.

23. White J. Preventing Suicide in Youth: Taking Action with Imperfect Knowledge. A Research Report Prepared for the British Columbia Ministry of Children and Family Development. Vancouver: Children's Mental Health Policy Research Program; 2005.

24. Prinstein MJ, Boergers J, Spirito A, Little TD, Grapentine W. Peer functioning, family dysfunction, and psychological symptoms in a risk factor model for adolescent inpatients' suicidal ideation severity. J Clin Child Psychol. 2000;29(3):392-405.

25. Winterrowd E, Canetto SS, Chavez EL. Friendships and suicidality among Mexican American adolescent girls and boys. Death Stud. 2010;34(7):641-660.

26. Lee K, Choi S, Kong J. The effects of parents-children dysfunctional communication and academic stress on adolescents' suicide ideationfocusing on the mediating effects of depression and gender differences. Korean Journal of Youth Studies. 2011;18(5):83-108. Korean.

27. Borges G, Nock MK, Haro Abad JM, et al. Twelve-month prevalence of and risk factors for suicide attempts in the World Health Organization World Mental Health Surveys. J Clin Psychiatry. 2010;71(12): 1617-1628.

28. Rehkopf DH, Buka SL. The association between suicide and the socioeconomic characteristics of geographical areas: a systematic review. Psychol Med. 2006;36(2):145-157.

29. Beck AT, Ward C, Mendelson M. An inventory for measuring depression. Arch Gen Psychiatry. 1961;4(6):561-571.
30. National Youth Policy Institute. A Study on Mental Health Improvement Policy for Children and Adolescents: General Report. 2011. Korean.

31. Galfalvi HC, Oquendo MA, Mann JJ. Evaluation of clinical prognostic models for suicide attempts after a major depressive episode. Acta Psychiatr Scand. 2008;117(4):244-252.

32. Picazo-Zappino J. Suicide among children and adolescents: a review. Actas Esp Psiquiatr. 2014;42(3):125-132.

33. Putkonen H, Komulainen E, Virkkunen M, Lönnqvist J. Female homicide offenders have greatly increased mortality from unnatural deaths. Forensic Sci Int. 2001;119(2):221-224.

34. Webb RT, Qin P, Stevens H, Mortensen PB, Appleby L, Shaw J. National study of suicide in all people with a criminal justice history. Arch Gen Psychiatry. 2011;68(6):591-599.

35. Wolff JC, Ollendick TH. The comorbidity of conduct problems and depression in childhood and adolescence. Clin Child Fam Psychol Rev. 2006;9(3-4):201-220.

36. Björkenstam E, Björkenstam C, Vinnerljung B, Hallqvist J, Ljung R. Juvenile delinquency, social background and suicide - a Swedish national cohort study of 992,881 young adults. Int J Epidemiol. 2011; 40(6):1585-1592.

37. Brent DA, Greenhill LL, Compton S, et al. The Treatment of Adolescent Suicide Attempters study (TASA): predictors of suicidal events in an open treatment trial. J Am Acad Child Adolesc Psychiatry. 2009;48(10): 987-996.

38. Ponnet K, Vermeiren R, Jespers I, et al. Suicidal behaviour in adolescents: associations with parental marital status and perceived parentadolescent relationship. J Affect Disord. 2005;89(1-3):107-113.

39. Gradus JL, Qin P, Lincoln AK, et al. Acute stress reaction and completed suicide. Int J Epidemiol. 2010;39(6):1478-1484.

40. Mathew A, Nanoo S. Psychosocial stressors and patterns of coping in adolescent suicide attempters. Indian J Psychol Med. 2013;35(1): 39-46.

41. Feskanich D, Hastrup JL, Marshall JR, et al. Stress and suicide in the Nurses' Health Study. J Epidemiol Community Health. 2002;56: 95-98.

42. Lazarus RS, Folkman S. Stress, Appraisal, and Coping. New York: Springer Publishing Company; 1984.

43. Bridge JA, Goldstein TR, Brent DA. Adolescent suicide and suicidal behavior. J Child Psychol Psychiatry. 2006;47(3-4):372-394.
Neuropsychiatric Disease and Treatment

\section{Publish your work in this journal}

Neuropsychiatric Disease and Treatment is an international, peerreviewed journal of clinical therapeutics and pharmacology focusing on concise rapid reporting of clinical or pre-clinical studies on a range of neuropsychiatric and neurological disorders. This journal is indexed on PubMed Central, the 'PsycINFO' database and CAS,

\section{Dovepress}

and is the official journal of The International Neuropsychiatric Association (INA). The manuscript management system is completely online and includes a very quick and fair peer-review system, which is all easy to use. Visit http://www.dovepress.com/testimonials.php to read real quotes from published authors. 